\title{
Acute Coronary Syndrome in Malaysian Octogenarian: Trends in Demographics and In- Hospital Managements
}

\section{Siti Zaleha Suki ( $\square$ sitizaleha_suki@yahoo.com )}

Department of Pharmacology, Universiti Malaya, 50603 Kuala Lumpur

\section{Ahmad Syadi Mahmood Zuhdi}

Cardiology Unit, Department of Medicine, Universiti Malaya, 50603 Kuala Lumpur

Abqariyah Yahya

Department of Social and Preventive Medicine, Universiti Malaya, 50603 Kuala Lumpur

Nur Lisa Zaharan

Department of Pharmacology, Universiti Malaya, 50603 Kuala Lumpur

\section{Research Article}

Keywords: Cardiovascular Disease, Mortality, Intervention, Pharmacotherapies, Pharmacoepidemiology

Posted Date: August 5th, 2021

DOl: https://doi.org/10.21203/rs.3.rs-737874/v1

License: (c) (i) This work is licensed under a Creative Commons Attribution 4.0 International License. Read Full License 


\section{Abstract}

Background: Octogenarians have often been neglected in the populational study of disease despite being at the highest point of non-modifiable disease risk burden and the fastest-growing age group for the past decade. This study examined the characteristics and in-hospital management of octogenarian patients with acute coronary syndrome (ACS).

Method: This retrospective study utilised the Malaysian National Cardiovascular Disease- ACS (NCVDACS) registry. Patients $\geq 80$ years old admitted with ACS at 23 participating hospitals from 2008 to 2017 $(n=3,080)$ were identified. Demographics, in-hospital intervention, and evidence-based pharmacotherapies were examined. Binary logistic regression was used.

Results: Octogenarians made up $3.8 \%$ of patients with ACS in the NCVD-ACS registry ( $53 \%$ men, mean age $=83.3, S D \pm 3.4)$ within the 10-year. The largest ethnic group was Chinese (44\%). Hypertension (78\%) was the main CV risk factor. Most octogenarians (90.4\%) have multiple CV risk factors. Non-ST-elevation myocardial infarction (NSTEMI) predominated $(38 \%, p<0.001)$. Only $10 \%$ of octogenarians with ACS underwent percutaneous coronary intervention $(\mathrm{PCl})$, the majority being STEMI patients $(17.5 \% ; p<0.05)$. More than $80 \%$ were prescribed aspirin (91.3\%) either alone or combined, dual antiplatelet therapy (DAPT) (83.3\%), anticoagulants (89.7\%) and statins (89.6\%), while less than half were prescribed angiotensinconverting enzyme inhibitors/angiotensin receptor blockers (47.6\%) and beta-blocker (43.0\%). From 2008 until 2017, there were positive increments in cardiovascular intervention and pharmacotherapies. Men were more likely to receive $\mathrm{PCl}$ than women (Odds Ratio (OR): $0.698 ; 95 \% \mathrm{Cl}: 0.490-0.993$ ). Those with NSTEMI (OR=0.402, 95\% Cl: 0.278-0.583) and unstable angina (UA) (OR=0.229, 95\% Cl: 0.143-0.366 were less likely to receive $\mathrm{PCl}$ but more likely to be given anticoagulants (NSTEMI, OR=1.543, 95\% Cl: 1.1112.142; $\mathrm{UA}, \mathrm{OR}=1.610,95 \% \mathrm{Cl}: 1.120-2.314)$ than STEMI octogenarians. The presence of cardiovascular risk factors and comorbidities influences management. For example, those with congestive heart failure were more likely to be given $\mathrm{PCl}$ and evidence-based pharmacotherapies.

Conclusion: Despite being the most vulnerable age group, octogenarians were conservatively treated with evidence-based treatment of ACS. As it is expected that the number of octogenarians with ACS will continue to increase thus the country needs to prepare to improve the management of this specific group of patients.

\section{Background}

The ageing population are increasing globally, a phenomenon known as the 'silver tsunami'. An estimated 125 million individuals were considered octogenarians in 2018, as they have reached 80 years and older (1). Cardiovascular disease (CVD) remains the leading cause of death in this population. The prevalence of CVD risk factors such as hypertension, diabetes mellitus (DM), and dyslipidaemia is also high in this age group, requiring appropriate prevention and intervention (2). There is a gap in evidence-based knowledge regarding the responses of octogenarian patients to interventions and pharmacotherapies. 
They are often neglected when evaluating the effectiveness of gaeriatric intervention in clinical trials and meta-analysis studies, making them poorly represented. At the same time, they are also at risk of adverse effects due to comorbidities and drug-drug interactions.

Malaysia is a multi-ethnic, upper-middle-income country in South-East Asia with a 32 million population (3). Malaysians aged 80 years and above are estimated to increase from 0.3 million in $2020(0.9 \%)$ to 1.4 million (1.7\%) by 2040 (4). The prolonged lifespan is contributed by its economic growth and public health development such as medical advances, better access to treatment and preventative measures (5). Like other countries, CVD is reported as the principal cause of death in the elderly in this country (6). There have been increases in facilities providing timely percutaneous coronary intervention ( $\mathrm{PCl}$ ) and trained cardiologists over the decades (7). However, CVD risk factors, such as diabetes mellitus (DM) and dyslipidaemia, remains high in the elderly (8). Less is known about the characteristics of patients and their cardiovascular management in the octogenarians.

This study aimed to examine the 10-year trend of octogenarian patients with ACS in Malaysia regarding patient characteristics and in-patient management, focusing on cardiac intervention and evidence-based pharmacotherapies. The data from the National Cardiovascular disease Database (NCVD) registry from 2008 to 2017 was utilised. The NCVD registry recorded information on patients with cardiovascular diseases from 2006 till current from 23 hospitals across Malaysia and provided valuable information on cardiovascular disease in this region of the world.

\section{Methods}

\section{Study population and ethical approval}

This cross-sectional descriptive study is part of research approved by the Medical Review and Ethics Committee (MREC), Malaysian Ministry of Health (MOH), with approval code of NMRR-19-4066-52389 (IIR). MREC waived informed consent for NCVD.

Data were obtained from the NCVD-ACS registry, which is part of the NCVD registry. This registry recorded vital information on patients with ACS, such as demographic and clinical information and their inhospital management, including cardiovascular interventions and medications. The details of this registry have been described elsewhere (9). It is being sponsored by the National Heart Association of Malaysia (NHAM) and the $\mathrm{MOH}$, with continuous training to ensure data quality. The yearly report of this database is made available to the public via the NHAM website.

\section{Patients and public involvement}

There was no patient or public participation in the development of this study's research question and outcome. All data were obtained retrospectively from the Malaysian NCVD-ACS registry.

\section{Patients characteristics}


Malaysian citizens aged 80 or older (known as octogenarian) diagnosed with ACS (ST-elevation myocardial infarction (STEMI, non-STEMI (NSTEMI) and unstable angina (UA)) based on the American College of Cardiology/American Heart Association (ACC/AHA) definitions (10) were identified from the NCVD registry from the year 2008 to $2017(n=3,080)$. Patient information obtained were demographics, risk factors, and co-morbidities as summarized in Table 1.

\section{Intervention and evidence-based pharmacotherapies}

In-hospital intervention and evidence-based pharmacotherapies were examined. Intervention includes coronary artery bypass graft (CABG) and percutaneous coronary intervention (PCl), both emergency and non-emergency $\mathrm{PCl}$. The five groups of drugs included in this study were (1) aspirin, (2) dual antiplatelet therapy (DAPT), (3) anticoagulants including unfractionated heparin (heparin), low-molecular-weight heparin (LMWH) and fondaparinux, (4) lipid-lowering agents (statins only), (5) angiotensin-converting enzyme inhibitors (ACEIs) and angiotensin receptor blockers (ARBs), and (6) beta-blockers.

\section{Statistical analysis}

Categorical variables are presented as frequencies and percentages. Comparisons between categorical variables were examined using the chi-square test. The variations in intervention and in-hospital pharmacotherapies were analysed using binary logistic regression, comparing the groups of interest, and presented as odds ratio (OR) with $95 \%$ confidence interval $(\mathrm{Cl})$. P-values of less than 0.05 is considered statistically significant. Statistical analysis was performed using Statistical Package for Social Science (SPSS) software (version 26.0, SPSS, Inc, Chicago, IL, USA).

\section{Results}

A total of 3,080 octogenarians ( $53 \%$ men, mean age 83.3, SD 3.374) had presented with ACS in the Malaysian NCVD-ACS registry from 2008 to 2017. The octogenarians made up 3.8\% of the total ACS patients cumulatively during the study period. The rates of octogenarians with ACS have increased significantly over the years ( $p<0.001)$, from $3.8 \%$ in 2008 to $17.8 \%$ in 2017 (Fig. 1). Chinese ethnicity made up most octogenarian ACS patients (44\%), with significant differences observed when comparing ethnic distribution across gender (Table 1). NSTEMI and UA made up more than two-thirds of ACS presentation in this group of patients. A gender difference was observed in ACS presentation $(p=0.001)$. For example, STEMI made up $31 \%$ of ACS presentation in men, but only $25 \%$ in women.

Hypertension was the highest recorded $\mathrm{CV}$ risk factor at $78 \%$, followed by diabetes mellitus at $43 \%$. There were significant differences in the $\mathrm{CV}$ risk factors profile between gender, with women having higher rates of hypertension, diabetes mellitus and dyslipidaemia. In comparison, men had higher rates of smokers and previous history of ischaemic heart disease (IHD). More than a third of patients already had more than three $\mathrm{CV}$ risk factors at presentation. CKD was the commonest comorbidities (14\%), followed by heart failure (12\%). Most patients were in Killip class 1 at presentation (56\%), with only $7 \%$ considered having cardiogenic shock. 
$\mathrm{PCl}$ intervention was performed at much higher frequencies (10\%) than CABG $(0.4 \%)$ in octogenarians with ACS (Table 2). Less than $13 \%$ of STEMI patients had undergone primary $\mathrm{PCl}$, while $60 \%$ received intravenous (IV) thrombolysis. However, an increased rate of octogenarians treated with PCl was found, from $5.1 \%$ in 2008 to $14.8 \%$ in 2017 (Fig. 1). For in-hospital pharmacotherapies, aspirin (91.3\%), DAPT (83.3\%), anticoagulants $(89.7 \%)$ and statins $(89.6 \%)$ were prescribed at near maximal levels, whilst less than half were being prescribed ACEIs/ARBs (47.6\%) and beta-blockers (43.0\%) (Table 2). The use of aspirin $(p=0.022)$ and DAPT $(p=0.014)$ was significantly higher in NSTEMI octogenarians than STEMI and UA. In general, most of the evidence-based pharmacotherapies have increased over the ten years (Fig. 2).

Octogenarian women with ACS were less likely to undergo PCl than men with an OR of $0.698(95 \% \mathrm{Cl}$ 0.490-0.993) (Table 3). NSTEMI and UA octogenarians were less likely to be intervened with PCI than STEMI (NSTEMI: OR $=0.402$ [95\% Cl 0.278-0.583]; UA: OR $=0.229$ [95\% $\mathrm{Cl} 0.143-0.366$ ) but they were more likely to receive anticoagulants (NSTEMI: OR $=1.543$ [95\% Cl 1.111-2.142]; UA: OR $=1.610$ [95\% Cl 1.120-2.314). NSTEMI octogenarians were also more likely to be prescribed with DAPT (OR $=1.658,95 \%$ $\mathrm{Cl}=1.157-2.375)$, while those with UA were more likely to be prescribed ACEIs/ARBs (OR $=1.482[95 \% \mathrm{Cl}$ $1.126-1.950])$, and beta-blockers ( $\mathrm{OR}=1.463[95 \% \mathrm{Cl} 1.112-1.924])$ than STEMI octogenarians. Octogenarians with known congestive heart failure were more likely to receive $\mathrm{PCl}$ and be prescribed statins, ACEls/ARBs and beta-blockers. Those with hypertension and previous history of IHD were more likely to be prescribed ACEIs/ARBs, while those with CKD were less likely to be prescribed beta-blockers.

\section{Discussion}

Octogenarians made up less than 5\% of patients in the NCVD-ACS registry from 2008 until 2017, whereby NSTEMI presentation predominated. The frequencies of men and women did not differ, and the largest ethnic group were Chinese. Hypertension was the main CV risk factor. Worryingly, most octogenarians (90.4\%) have multiple CV risk factors. The rates for in-hospital PCl has been increasing. There was a high percentage of patients prescribed anticoagulants, antiplatelets and lipid-lowering agents. However, less than half were being prescribed ACEls/ARBs and beta-blockers. The presence of $\mathrm{CV}$ risk factors and comorbidities influences management. For example, those with congestive heart failure were more likely to be given $\mathrm{PCl}$ and evidence-based pharmacotherapies.

Malaysia is experiencing an increasing trend of the elderly population, which have surpassed 15 per cent. This change would burden the country's economy due to increasing healthcare services demand (11). This study found increasing trend in the octogenarians with ACS. Age-related changes in vascular wall elasticity, coagulation and haemostatic system and endothelial functions become more apparent in this age group. The Swedish National registry reported that the cumulative incidence of MI, stroke and CVD mortality for those aged 80 years old and above are the highest amongst other age groups observed (12). Thus, the octogenarians represent an important group for policymakers to focus on in the coming years. 
Although no significant differences were observed in gender presentation for ACS in the octogenarians, the rates of $\mathrm{CV}$ risk factors differed. There were higher rates of hypertension, diabetes mellitus and dyslipidaemia in women, while men had higher smokers and previous history of IHD. This finding is similar to the national health survey for adults in 2015 (13). The largest ethnic group in this pool of patients were Chinese, in contrast to the demographic distribution of the country, where Malays are the majority (14). This ethnic variation was also different from the ACS demographics in younger age groups, using the same registry (15). The Chinese predominance could be due to several reasons such as longer lifespan, healthier lifestyle and geographical location. The Chinese reside primarily in urban areas where healthcare services are nearby (16). They have the lowest prevalence of CV risk factors and physical inactivity than other ethnicities $(17,18)$.

There is a high prevalence of octogenarians with multiple risk factors. These risk factors may affect the presentation and the severity of $\mathrm{CHD}$ and the complexity of managing them. Hypertension remains the major risk factor. Thus, advocating evidence-based management to treat hypertension may result in a more favourable outcome (19). More than forty per cent of patients have diabetes mellitus, which is higher than observed in other populations in the African, European, Northern America and the Western Pacific region (20). Diabetes mellitus on its own is associated with other comorbidities such as chronic kidney disease and thus needs to be managed carefully in this group of patients. Comorbidities such as congestive heart failure have also influenced the choice of management of ACS in these patients.

This study showed an increasing trend of $\mathrm{PCl}$ in octogenarians with STEMI. The advantages of $\mathrm{PCl}$ is debatable in old age. The most common non-cardiac complication of $\mathrm{PCl}$ is bleeding, associated with a higher risk of death in the elderly, especially in the presence of comorbidities (21). Despite this, studies have shown the benefits of $\mathrm{PCl}$ in this group. The Global Use of Strategies to Open Occluded Coronary Arteries in Acute Coronary Syndromes (GUSTO IIb) trial found a strong trend of lower 30-days mortality rates in patients $\geq 70$ years old treated with $\mathrm{PCl}$, compared to thrombolysis (22). PCl-treated patients had higher target vessel revascularisation at follow-up in the Primary Coronary Angioplasty Trial (PCAT) (23), suggesting acceptable long-term outcomes for octogenarians (24). CABG was not preferred in our population, most likely influenced by their frailties and comorbidities (25). The rate of PCl will likely continue to increase in the coming years; therefore, skilled cardiologists and equipped facilities are essentials.

The treatment for NSTEMI and UA is mainly through pharmacotherapies proposed by internationally approved guidelines such as antiplatelets and anticoagulants (26-28). This practice is reflected in this study, whereby NSTEMI and UA were less likely given PCI but more likely to receive anticoagulants than STEMI. Interestingly, the 'After Eighty' study has suggested that participants with NSTEMI and UA may have better outcomes with higher success rates and lesser complication after $\mathrm{PCl}$ procedures compared to those treated with optimum medical treatment alone (29).

The evidence-based pharmacotherapies for immediate ACS treatment include antiplatelets, anticoagulants, statins, ACEIs/ARBs and beta-blockers. Those who received recommended therapies were 
shown to have lower in-hospital mortality than those who did not (30). Antiplatelets were prescribed maximally in this population. Aspirin has been used in ACS for decades $(28,31)$. Recently, guidelines recommended the use of DAPT (28). The prescribing of DAPT has increased in octogenarian patients. Bleeding remains a significant adverse effect for DAPT. There is still room for improvement for ACEls/ARBs and beta-blockers in this population. Similar trends were seen in the younger age group in the NCVD-ACS registry $(15,32)$. The CRUSADE study reported that beta-blockers were also less likely to be prescribed in elderly patients (30). Physicians need to be aware of age-related physiological changes that may affect the pharmacokinetics and pharmacodynamics of these drugs in octogenarians while considering the immediate and long-term benefits.

We need to bridge the knowledge gap on the effectiveness and risks of current management by performing clinical studies in the local setting. An example that could be modelled is Finland's follow-up accumulation of risk factor study (33) and the After Eighty case-control study. As ACS has a multifactorial aetiology, a modelling study could be performed to investigate the contributions of each risk factor and how management impacted the outcomes. One example is the IMPACT-CHD model used in the Italian and Portugal population that have shown death prevented and postponed in women aged $\geq$ 75 were higher than men $(34,35)$. At these bonus plus years that the octogenarians currently enjoy, dipping into already scarce resources, the question most would not dare to ask is, "is it worth spending so much only to prolonged something inevitable?".

\section{Strength and limitations}

This study uses data from a nationwide cardiology registry obtained from 23 hospitals to represent an unselected group of octogenarian patients with ACS in a real-world setting in this country. The database is well maintained, and training is provided regularly for those involved to ensure data quality (36-38). Information that measures socioeconomic status may influence demographics presentation, such as occupation and educational levels, were not available. However, most octogenarians are often retired. Participation of hospitals in this database is voluntary, and there may be a selection bias. Many private hospitals did not participate in this registry. Thus, the pattern of octogenarians with ACS in this sector could not be determined. However, private hospitals mainly cater for self-paying or health insurance schemes; therefore, the utilisation in octogenarians may be less than other age groups due to financial restrictions at this extreme age.

\section{Conclusion}

As octogenarians with ACS continue to increase, the country needs to plan for disease management and prevention. Ideally, the intensity of intervention should be proportional to the total risk. Despite being the most vulnerable age group, octogenarians were not receiving aggressive treatment as younger patients. The use of evidence-based pharmacotherapies was maximised instead. It is expected that management will continue to improve in the coming years with an increasing number of octogenarians, better technologies and knowledge of the disease in this age group. 


\section{Declarations}

Acknowledgements

We would like to thank all the medical and non-medical staff involved in the data collection and organization of NCVD and NHAM Malaysia.

\section{Funding}

The author has not declared a specific grant for this research from any funding agency in the public, commercial or not-for-profit sectors.

\section{Availability of data and materials}

No data are available.

\section{Ethics approval and consent to participate}

The NCVD registry study was approved by the Medical Review \& Ethics Committee (MREC), Ministry of Health (MOH) Malaysia in 2007 (Approval Code: NMRR-07-20250). MREC waived informed consent for NCVD. This study is a part of research approved by MREC with Approval Code: NMRR-19-4066-52389 (IIR).

\section{Competing interests}

None declared.

\section{Consent for publication}

Not applicable

\section{Authors contribution}

The original idea of the study originated from Suki SZ and Zaharan NL designed the study. Suki SZ performed all data and statistical analysis. All authors interpreted the results. Suki SZ wrote the initial draft of the manuscript. Zaharan NL revised the manuscript. All authors scrutinized the final manuscript.

\section{References}

1. United Nations DoEaSA, Population Division World Population Ageing 2015 (ST/ESA/SER.A/390). 2015.

2. O'Gara PT, Kushner FG, Ascheim DD, Casey DE, Jr., Chung MK, de Lemos JA, et al. 2013 ACCF/AHA guideline for the management of ST-elevation myocardial infarction: a report of the American College of Cardiology Foundation/American Heart Association Task Force on Practice Guidelines.

Circulation. 2013;127(4):e362-425. 
3. STATISTICS ON CAUSES OF DEATH, MALAYSIA, 2018 [Internet]. 2018.

4. Ibrahim WMSW AS, Othman NH, Zukri SFM, Anwar R, Miskiman N, Daud S, Shukor FAZA. Ageing. Population and Demographics [Internet]. 2017 [cited 202021 Dec 2020].

5. Cherubini A, Corsonello A, Lattanzio F. Underprescription of Beneficial Medicines in Older People. Drugs \& Aging. 2012;29(6):463-75.

6. Statistics on Causes of Death, Malaysia, 2019 [Internet]. Department of Statistics Malaysia. 2019.

7. Annual Report of the NCVD-PCI Registry, Year 2015 - 2016. . Kuala Lumpur, Malaysia; 2018.

8. Institute for Public Health MoH, Malaysia. National Health And Morbidity Survey 2019: NonCommunicable Diseases, Healthcare Demand And Health Literacy. Malaysia: Institute for Public Health, Ministry of Health, Malaysia; 2019.

9. Ahmad WA, Ali RM, Khanom M, Han CK, Bang LH, Yip AF, et al. The journey of Malaysian NCVD-PCI (National Cardiovascular Disease Database-Percutaneous Coronary Intervention) Registry: a summary of three years report. International journal of cardiology. 2013;165(1):161-4.

10. Malaysia MoH. Clinical Practice Guidelines Primary \& Secondary Prevention of Cardiovascular Disease 2017. Malaysia: Ministry of Health Malaysia; 2017. p. 182.

11. Frankel S, Ebrahim S, Davey Smith G. The limits to demand for health care. BMJ. 2000;321(7252):405.

12. Jernberg T, Hasvold P, Henriksson M, Hjelm H, Thuresson M, Janzon M. Cardiovascular risk in postmyocardial infarction patients: nationwide real world data demonstrate the importance of a longterm perspective. Eur Heart J. 2015;36(19):1163-70.

13. Ahmad NA, Mohamad Kasim N, Mahmud NA, Mohd Yusof Y, Othman S, Chan YY, et al. Prevalence and determinants of disability among adults in Malaysia: results from the National Health and Morbidity Survey (NHMS) 2015. BMC Public Health. 2017;17(1):756.

14. Department of Statistics Malaysia. Population Projection (Revised), Malaysia, 2010-2040 Department of Statistics, Malaysia: Department of Statistics, Malaysia; 2016

15. Venkatason P, Zubairi YZ, Hafidz I, Wan WA, Zuhdi AS. Trends in evidence-based treatment and mortality for ST elevation myocardial infarction in Malaysia from 2006 to 2013: time for real change. Ann Saudi Med. 2016;36(3):184-9.

16. Safurah Jaafar KMN, Khairiyah Abdul Muttalib, Nour Hanah Othman, Judith Healy. Malaysia health system review. 2012.

17. ABRIDGED LIFE TABLES, MALAYSIA, 2017-2019 [press release]. Malaysia: Department of Statistics Malaysia, 23 July 20192019.

18. Teh JK, Tey NP, Ng ST. Ethnic and gender differentials in non-communicable diseases and self-rated health in Malaysia. PLoS One. 2014;9(3):e91328.

19. Roger VL, Go AS, Lloyd-Jones DM, Adams RJ, Berry JD, Brown TM, et al. Heart disease and stroke statistics-2011 update: a report from the American Heart Association. Circulation. 2011;123(4):e18e209. 
20. Einarson TR, Acs A, Ludwig C, Panton UH. Prevalence of cardiovascular disease in type 2 diabetes: a systematic literature review of scientific evidence from across the world in 2007-2017. Cardiovascular Diabetology. 2018;17(1):83.

21. Feldman DN, Gade CL, Slotwiner AJ, Parikh M, Bergman G, Wong SC, et al. Comparison of outcomes of percutaneous coronary interventions in patients of three age groups $(<60,60$ to 80 , and $>80$ years) (from the New York State Angioplasty Registry). Am J Cardiol. 2006;98(10):1334-9.

22. Global Use of Strategies to Open Occluded Coronary Arteries in Acute Coronary Syndromes Angioplasty Substudy I. A clinical trial comparing primary coronary angioplasty with tissue plasminogen activator for acute myocardial infarction. N Engl J Med. 1997;336(23):1621-8.

23. Grines C, Patel A, Zijlstra F, Weaver WD, Granger C, Simes RJ, et al. Primary coronary angioplasty compared with intravenous thrombolytic therapy for acute myocardial infarction: six-month follow up and analysis of individual patient data from randomized trials. Am Heart J. 2003;145(1):47-57.

24. Conrotto F, Scacciatella P, D'Ascenzo F, Chieffo A, Latib A, Park SJ, et al. Long-term outcomes of percutaneous coronary interventions or coronary artery bypass grafting for left main coronary artery disease in octogenarians (from a Drug-Eluting stent for LefT main Artery registry substudy). Am J Cardiol. 2014;113(12):2007-12.

25. Lee MMY, Petrie MC, Rocchiccioli P, Simpson J, Jackson CE, Corcoran DS, et al. Invasive versus medically managed acute coronary syndromes with prior bypass (CABG-ACS): insights into the registry versus randomised trial populations. Open Heart. 2021;8(1):e001453.

26. Roffi M, Patrono C, Collet JP, Mueller C, Valgimigli M, Andreotti F, et al. 2015 ESC Guidelines for the management of acute coronary syndromes in patients presenting without persistent ST-segment elevation: Task Force for the Management of Acute Coronary Syndromes in Patients Presenting without Persistent ST-Segment Elevation of the European Society of Cardiology (ESC). Eur Heart J. 2016;37(3):267-315.

27. Amsterdam EA, Wenger NK, Brindis RG, Casey DE, Jr., Ganiats TG, Holmes DR, Jr., et al. 2014 AHA/ACC Guideline for the Management of Patients with Non-ST-Elevation Acute Coronary Syndromes: a report of the American College of Cardiology/American Heart Association Task Force on Practice Guidelines. J Am Coll Cardiol. 2014;64(24):e139-e228.

28. Arnett DK, Blumenthal RS, Albert MA, Buroker AB, Goldberger ZD, Hahn EJ, et al. 2019 ACC/AHA Guideline on the Primary Prevention of Cardiovascular Disease: A Report of the American College of Cardiology/American Heart Association Task Force on Clinical Practice Guidelines. Circulation. 2019;140(11):e596-e646.

29. Tegn N, Eek C, Abdelnoor M, Aaberge L, Endresen K, Skardal R, et al. Patients aged 80 years or older with non-ST-elevation myocardial infarction or unstable angina pectoris randomised to an invasive versus conservative strategy: angiographic and procedural results from the After Eighty study. Open Heart. 2020;7(2).

30. Alexander KP, Roe MT, Chen AY, Lytle BL, Pollack CV, Jr., Foody JM, et al. Evolution in cardiovascular care for elderly patients with non-ST-segment elevation acute coronary syndromes: results from the 
CRUSADE National Quality Improvement Initiative. J Am Coll Cardiol. 2005;46(8):1479-87.

31. Marcucci R, Patti G, Calabro P, Gori AM, Grossi G, Cirillo P, et al. Antiplatelet treatment in acute coronary syndrome patients: Real-world data from the START-Antiplatelet Italian Registry. PLoS One. 2019;14(7):e0219676.

32. Venkatason P, Zaharan NL, Ismail MD, Wan Ahmad WA, Mahmood Zuhdi AS. Trends and variations in the prescribing of secondary preventative cardiovascular therapies for non-ST elevation myocardial infarction (NSTEMI) in Malaysia. Eur J Clin Pharmacol. 2018;74(7):953-60.

33. Reinikainen J, Laatikainen T, Karvanen J, Tolonen H. Lifetime cumulative risk factors predict cardiovascular disease mortality in a 50-year follow-up study in Finland. International Journal of Epidemiology. 2014;44(1):108-16.

34. Palmieri L, Bennett K, Giampaoli S, Capewell S. Explaining the decrease in coronary heart disease mortality in Italy between 1980 and 2000. Am J Public Health. 2010;100(4):684-92.

35. Pereira M, Azevedo A, Lunet N, Carreira H, O'Flaherty M, Capewell S, et al. Explaining the decline in coronary heart disease mortality in Portugal between 1995 and 2008. Circ Cardiovasc Qual Outcomes. 2013;6(6):634-42.

36. Manghani K. Quality assurance: Importance of systems and standard operating procedures. Perspect Clin Res. 2011;2(1):34-7.

37. Arts DG, De Keizer NF, Scheffer GJ. Defining and improving data quality in medical registries: a literature review, case study, and generic framework. J Am Med Inform Assoc. 2002;9(6):600-11.

38. Gliklich RE DN, Leavy MB, editors. . Registries for Evaluating Patient Outcomes: A User's Guide [Internet]. 2014. In: Data Collection and Quality Assurance [Internet]. US: Rockville (MD): Agency for Healthcare Research and Quality 3rd Edition.

\section{Tables}

Due to technical limitations, table 1 to 3 PDFs are only available as a download in the Supplemental Files section.

\section{Figures}




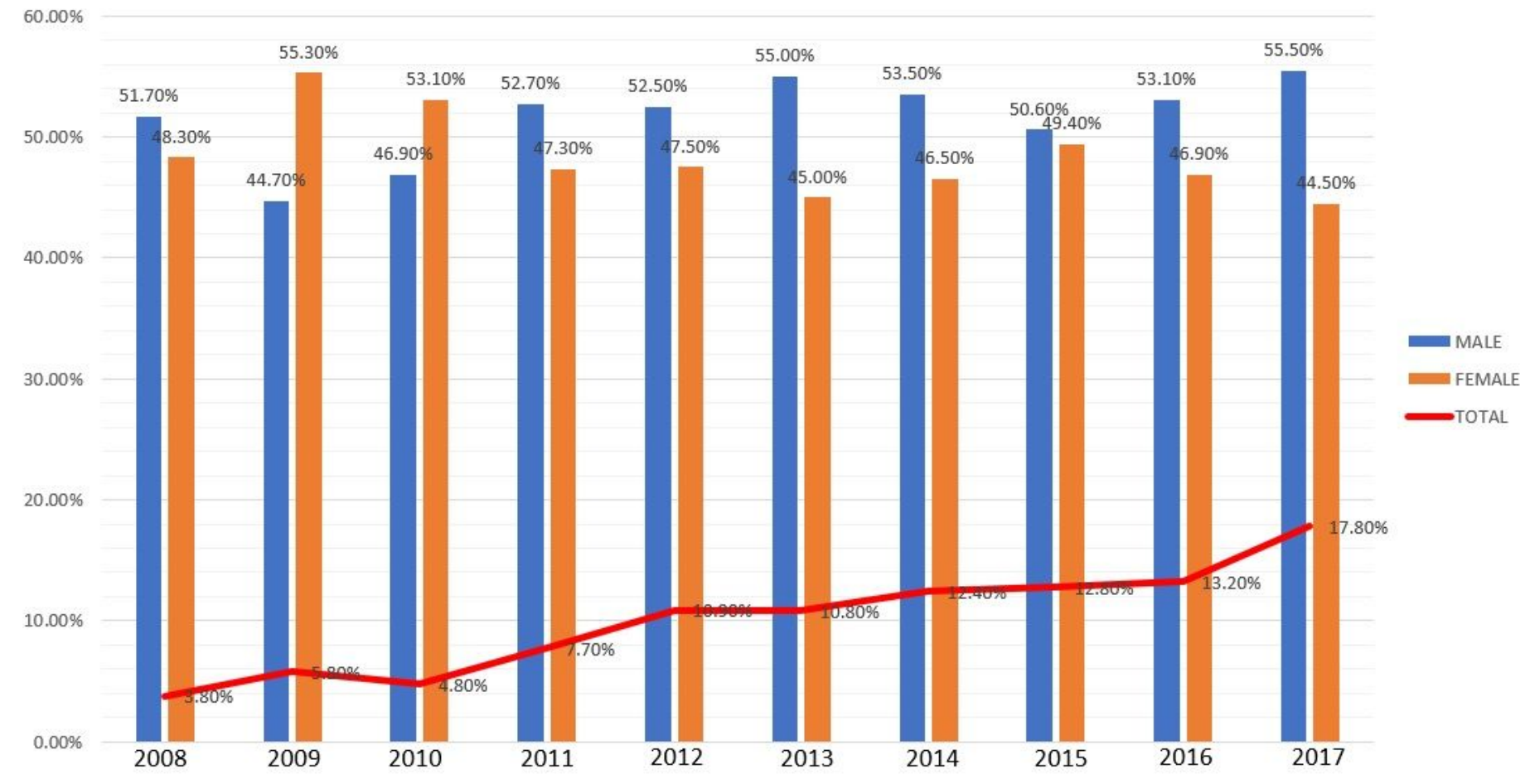

Figure 1

ACS octogenarian trends and gender frequencies as reported in the Malaysian NCVD-ACS registry (20082017). 10 -years cumulative $N=3,080$ comprises of 1,618 octogenarians men and 1,462 octogenarians women. 
Frequencies of in-hospital pharmacotherapies (NCVD:2008-2017)

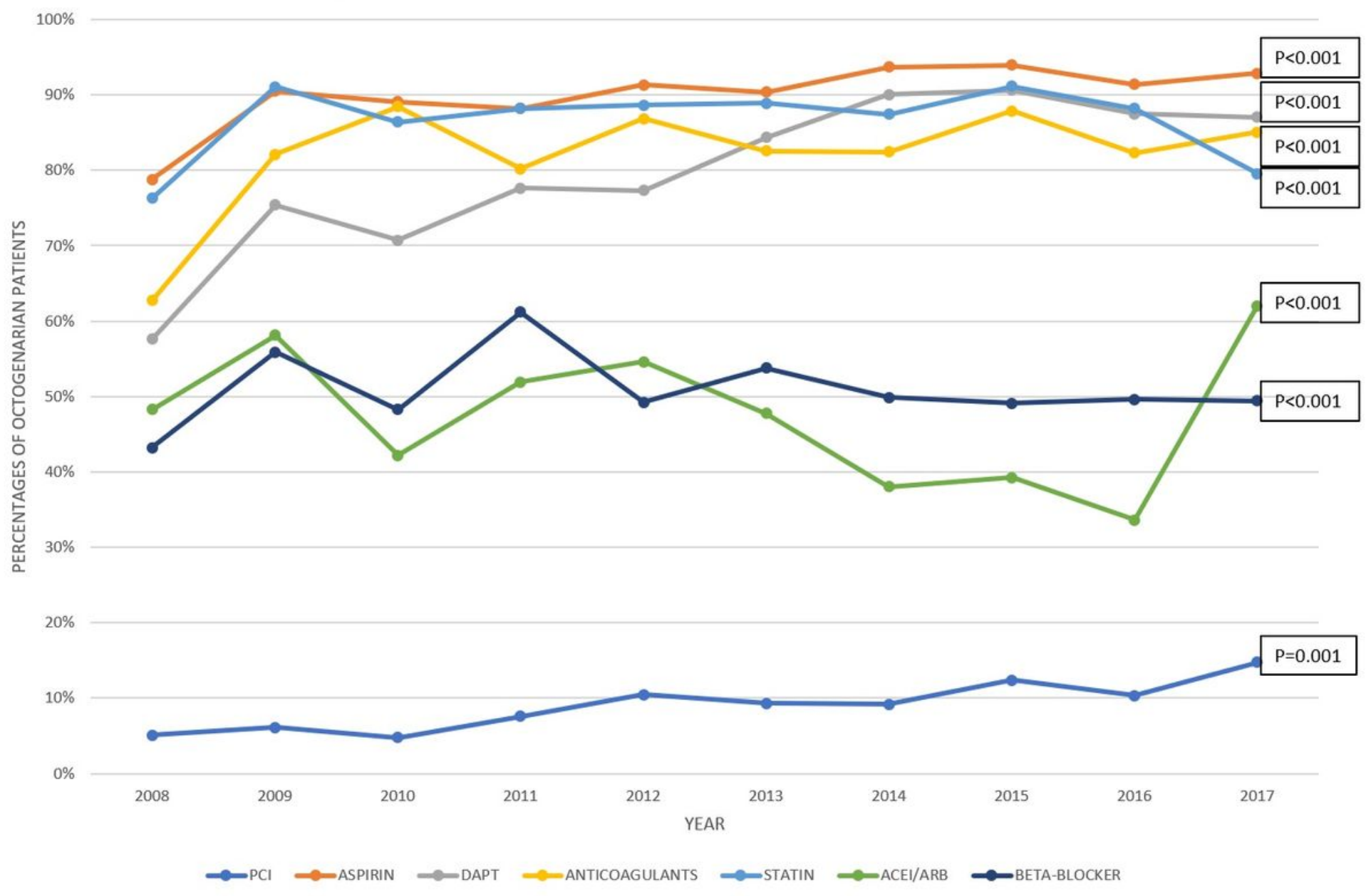

Figure 2

Frequencies of $\mathrm{PCl}$ and in-hospital evidence-based pharmacotherapies prescribed to octogenarian as reported in Malaysian NCVD-ACS registry (2008-2017). In-hospital pharmacotherapies includes aspirin, dual antiplatelet therapy (DAPT), anticoagulants, statins, ACE inhibitors(ACEi)/ angiotensin II receptor blockers (ARB) and beta blocker prescription are exclusively recorded. P-value of significance for each pharmacotherapies were analyzed throughout the 10-years observation.

\section{Supplementary Files}

This is a list of supplementary files associated with this preprint. Click to download.

- SitiZalehaSukiTable1.pdf

- SitiZalehaSukiTable2.pdf

- SitiZalehaSukiTable3.pdf 